Stress incontinence, when due to weakness of the sub-urethral tissues, can in most cases be cured by a plastic re-inforcing operation. This satisfactory procedure should always be undertaken if the trouble is not of recent origin and provided that the test described under "Diagnosis" promises success. In a case, however, where the weakness follows immediately after parturition, in a young woman electrical treatment should be tried; it often effects a cure if begun soon after the injury and is preferable to performing plastic work which may be undone by subsequent child-bearing.

Fistulae. The treatment here is surgical, but it is generally agreed that operative repair of those opening from the bladder into the vagina is a difficult and often disappointing procedure, sometimes requiring several attempts. The outlook depends on the size of the defect, on its position and on its original cause. It is hardly necessary to say that repair of a large opening is very difficult, involving as it does wide undercutting to separate the two organs and to prevent tension when the edges of the hole in the bladder are drawn together; if there is any dragging at the end of the operation the stitches will inevitably cut out to some extent. It is best to warn the patient at the beginning that, although the defect may be reduced in size by a first approach, more than one operation will almost certainly, be necessary. With regard to position, a fistula on the base offers more hope of early success than does one on the trigone or inter-ureteric bar owing to the normal fixation of these tissues to the vagina, the close proximity of the ureters and the consequent difficulty of mobilisation. Again a large fistula may be adherent to the pubic bone. Fixed rules cannot be made but, generally speaking, it is best to approach a fistula on the bladder base by suprapubic cystotomy, and one on the trigone from the vagina. As to the cause, fistulae due to radium burns are exceptionally difficult to mend as there appears to be no life or healing power left in the tissues; even if success seems assured in the early stages a fresh breakdown may easily occur later, so a very cautious prognosis must be given. In these cases or where the destruction is extensive, perhaps combined with bone fixation, it is better to make no local attempt but to transplant the ureters into the pelvic colon, thus excluding the bladder and turning the rectum into a reservoir for urine as well as for faeces. If an ectopic ureteric opening or a uretero-vaginal fistula exists the ureter should be re-implanted into the bladder unless the corresponding kidney is markedly hydronephrotic, in which case nephrectomy should be performed provided that the second kidney is healthy. Surgical repair is also undertaken for a urethral fistula and the sphincter, if injured, is repaired, though this again may be difficult. If the sphincter has been totally destroyed or is paralysed from failure of the nerve supply ureteric implantation into the colon is the only way to obtain relief.

Congenital deformities of the bladder and urethra are treated by plastic operations designed to meet the particular requirements of the case.

Enuresis in adults is a condition for which no really satisfactory treatment has yet been discovered. In the pre-menstrual type an alteration of the internal secretion balance may be tried and sometimes helps, but where the incontinence occurs at any time and for no apparent reason the clinician can only attempt one remedy after another and is very lucky if any measure of success is attained. Ephedrine in quarter-grain tablets three times daily with an extra one at bedtime has sometimes been found helpful.

\title{
DISORDERS OF MICTURITION IN CHILDHOOD
}

\author{
By J. VERNON BRAITHWAITE, M.D., F.R.C.P. \\ (Physician in charge of Paediatric Department, Leicester Royal Infirmary)
}

It is rather remarkable how seldom a mother will admit that her child passes urine normally. To the routine questions of case-taking her answers come readily and decisively until she is asked, "Does he (or she) pass water normally?" After a moment's hesitation the reply will be made to the effect that the child passes urine either too frequently or not often enough; or that the act is accompanied by manifestations of discomfort; that micturition is precipitate, or that there is faulty control. There are various reasons for this. One is that disorders of micturition are quite common in infancy and childhood, and are not infrequently accepted with a fatalistic resignation, and not mentioned until a direct question is asked. Another is that many mothers fear that the genito-urinary apparatus of the child is not quite normal, but hesitate to give 
voice to their fears. Again, the complaint may be due to the fact that strong emotion is often associated with emptying the bladder in the very young. Crying and micturition occur simultaneously, and the mother tells us that "he cries when he passes water," when she would be more accurate if she said "he passes water when he cries." Incidentally, violent laughter is also frequently accompanied by the act; moreover, emptying the bladder pleases the young child, who not infrequently gives a smile of gratification at the time. Curiously enough, however, the complaint that "he laughs when he passes water" is seldom, if ever, made; but laughter is seldom associated in the lay mind with pathological processes.

The object of this paper is to give some account of the more common disorders of micturition in childhood, and to discuss their treatment. But it is obviously important to outline what are abnormalities-or rather, to give the variations of normality-before attempting this. The baby passes from I4 to I7 ozs. of urine in the 24 hours, and the frequency of micturition varies from four or six to even thirty or forty times a day. It is at first an involunary reflex act, but voluntary control is gradually acquired. Diurnal control should be established between I 8 months and $2 \frac{1}{2}$ years. The child should certainly be dry at nights at the age of three, and usually this is attained considerably before this. When such a stage has been reached the bladder is usually emptied six to eight times in the twenty-four hours, the total amount passed being from $I$ to $2 \frac{1}{2}$ pints.

The mechanism of micturition is complicated, being partly reflex and partly voluntary. The bladder musculature consists of three parts; an outer longitudinal layer, the detrusor; a middle circular layer, best marked at the base, where it forms the internal sphincter; and a thin internal longitudinal layer. The proximal part of the urethra is also surrounded by muscle, which is here striped, the bulbo-spongiosus and the sphincter urethri. Normally, intravesical pressure is kept constant at about I5 c.c. of water. As more urine is passed into the organ from the ureters, the detrusor relaxes and normal pressure is maintained. This proceeds without the individual being conscious of it, so long as the pressure is maintained at 15 c.c. of water. There comes a time, however, when the detrusor fails to relax and pressure begins to rise. When it reaches $I 8$ c.c. the desire to micturate is produced. Rhythmic contractions take place, but impulses from the higher centres via the sympathetic cause further relaxation of the detrusor, the pressure falls, and the desire to empty the bladder passes for a time. When a conveniento opportunity presents itself, intra-abdominal pressure is voluntarily raised by the closing of the glottis and forcible depression of the diaphragm, intra-vesical pressure rises to $20-30$ c.c. of water, and a few drops of urine are forced into the posterior urethra. This causes a massive reflex contraction of the detrusor, and the bladder is emptied.

The nervous control of this mechanism is supplied by the sympathetic and the parasympathetic. The parasympathetic pelvic nerves come from the Ist, 2nd and 3 rd sacral segments and cause contraction of the detrusor and relaxation of the sphincter. The sympathetic fibres run in the ilio-hypogastric nerves from the Ist and and lumbar segments and reduce the tone of the bladder musculature, but cause contraction of the sphincter. The bulbospongiosus and sphincter urethra are supplied by somatic fibres from the pudic nerve. These muscles contract at the end of micturition and empty the urethra; they may also act as an additional sphincter when the sphincter vesical is inhibited or damaged.

The amount passed at each act varies enormously from an ounce or less in the infant to ten ounces or more in some older children. If the bladder fills quickly the desire to micturate is produced by a smaller amount of urine than when filling is slow. Thus polyuria produces frequency out of proportion to the amount of urine passed, and similarly when little urine is secreted large amounts accumulate in the bladder before the organ is emptied.

In such a complicated mechanism disorders are sure to be frequent, and especially will they occur in young children in whom the nervous control is ill-developed, infections are common, and conflicting emotions are centred round the act. These disorders fall into four main groups:-

I. Retention.

2. Incontinence.

3. Frequency.

4. Dysuria.

Not uncommonly two or more of these symptoms may be combined.

r. Retention is an uncommon symptom in early life. Usually it is one of the manifestations of serious organic disease of the nervous system-e.g. encephalo-myelitis following measles. 
Sometimes it is an hysterical manifestation, when it may result from an excessive emotional reaction to some temporary loss of control. Occasionally one meets with a case of spasm of the sphincter, caused by sudden chilling, cystitis, or vesical calculus. Straining without micturition is the only symptom. The condition is treated by removing the cause, and by the exhibition of belladonna or hyoscyamus.

An important but not very common cause of retention in the newly-born is the presence of a valve-like fold in the urethra or hypertrophy of the verumontanum. In addition to absent or very much reduced micturition, there is marked dilatation of the bladder and bilateral hydronephrosis, which is shown by a tumour in both flanks. Sooner or later uraemia develops if the condition is not relieved. There is no difficulty in passing a catheter, as the valve is directed upwards. Treatment is surgical, the ureters and bladder being gradually decompressed and the valve or verumontanum removed through a cystoscope.

2. Incontinence, when complete, is associated with serious organic disease of the spinal cord, and is fortunately rare. The commonest cause in childhood is spina bifida, in which the cord is adherent to the skin. Intermittent incontinence, or enuresis, on the other hand, is one of the commonest complaints of childhood. This is essentially a psycho-somatic disorder. In the opinion of many it is a purely psychological complaint, but if this were so one would expect acquired cases to be in the great majority, whereas nearly all are congenital-control has never been properly established.

The sexes are affected equally. There is often a family history of the complaint. As a rule the children are bright and intelligent. Sometimes, however, they appear dull and apathetic, which may be due to the attitude of their parents towards their affliction-punishment, either corporal or psychological, having been freely administered, and the personality of the child rendered stubborn and resentful. The little patients are usually very ashamed of the whole business, and dislike it being discussed in the presence of a third person. The majority of children with enuresis only lose control of the bladder during sleep, but even in the daytime have great urgency and frequency of micturition. Sometimes this amounts to actual diurnal loss of control. The time of wetting the bed varies considerably. Sometimes it occurs immediately after going to sleep, sometimes not until the early hours of the morning, sometimes it happens several times a night. Sleep is usually profound, and this depth of sleep is undoubtedly a factor in the production of the symptom. As a rule spontaneous cure occurs at or after puberty, but this is by no means always the case, and many adults live an unhappy life due to enuresis because they are too shy to consult a doctor about their trouble.

I believe that there are four factors in the production of enuresis. The first and most important is an achalasia, or absence of relaxation, of the detrusor. This is accompanied by a depression of the tone of the sphincter, so that bladder pressure rises with a smaller amount of urine than normal, and a few drops are more easily expelled in the posterior urethra, which results in a mass contraction and emptying of the organ. The second is a greater depth of sleep than normal, so that afferent impulses from the bladder fail to awaken the patient. The third is an abnormal psychological state, which arouses an unconscious desire to return to the infantile state-for instance, when another child arrives and gets an undue amount of attention owing to his tender age; the patient thus has the advantages of infancy continually presented to him. The fourth and last is some abnormality of the lower urinary tract, such as obstruction of the urinary outflow, meatitis, or vulvitis. Here it may be stated that phimosis, fancied or factual, has no part in the production of enuresis, and circumcision will not cure it.

Diagnosis presents no difficulty, but one must be on one's guard not to miss masked epilepsy. It will usually be found that epileptics do not have diurnal frequency; indeed, they seem to have the power of retaining a larger amount of urine in their bladders than normal children. Careful enquiry will usually elicit the history of attacks of at least petit mal in an epileptic child. It is doubtful if enuresis is ever the only symptom of this disease. Spina bifida occulta may be present, but it is very doubtful if it has anything to do with the production of bed wetting if diurnal control is unaffected. The incidence of this deformity among enuretics is not greater than among the normal population.

\section{Treatment.}

The above four factors, detrusor achalasia, abnormally deep sleep, neurosis, and local lesions, must all be eliminated or treated if enuresis is to be cured, and frankly this often presents 
no small difficulty. Perseverance and thoroughness, however, will give good results in a gratifying number of cases.

To overcome the abnormality of the detrusor, antispasmodics, such as belladonna and $>$ ephedrin, in full doses, are given. The patient should be encouraged to increase the intervals $\stackrel{\mathbb{Q}}{\circ}$ between the acts of voiding during the day, and should also be told voluntarily to stop the $C$. stream once or twice during micturition-a sort of sphincter drill. If diurnal frequency is $\overrightarrow{\vec{F}}$ very severe-and some of these children are running out to empty their bladders every few $\stackrel{\text { ? }}{+}$ minutes-and if these measures are unsuccessful, sometimes dramatic relief will follow graduated distention of the bladder with sterile warm boracic solution. The amount of urine that the child passes at each act of micturition is measured. A soft rubber catheter is passed, and by means of a two-way syringe a slightly larger amount is injected. This is repeated two or three times a week, the amount being gradually increased.

Rendering sleep less profound is best secured by giving benzedrine. The dose needs careful adjustment; 5 mgms. on retiring is a satisfactory starting point, but this may keep some children awake, while it will have no effect on others. The good results reported by some observers from the use of thyroid extract may be due to the stimulating effect of the drug in this direction, or to its action on the sympathetic supplying the sphincter.

Every case of enuresis needs psychotherapy, but it is seldom necessary to refer the patient $\exists$ to the psychiatrist. Griffiths and Mitchell's (I94I) five psychological needs of childhood should i be memorised, and the physician should see they are being met in each patient. They are as follows:-

Every child should have or fondling.

(I) a feeling of belongingness in his family group. Parents should inculcate this by cuddling

(2) A certain degree of extroversion-doing and making things, finding outlets in concrete rather than abstract interests.

(3) An adjustment within the group which will make him both a follower and a leader.

(4) Experience in self-sufficiency-every child should spend some part of each day alone.

(5) Experience in being needed - he must see that the family actually depends upon him for some part of its life.

It will usually be found that one or more of these activities needs adjustment. If the child is profoundly neurotic it may be necessary to refer him for some such treatment as plas. therapy under skilled observation. But often this will relieve the neurosis, but leave the organic part of the enuresis untouched. Play therapists tell me that enuretics almost invariably elect to play with water, and I have seen a small boy with this complaint spend days on end emptying a jug by means of a Higginson's syringe. He became happy, cheerful, and obedient-was he not realising his life's major ambition, to control the water?-but he still wet the bed every night! Anything which gives the child a dry night can be used for its psychological effectrestricting fluids in the evening, lifting the child once or twice during the night to pass urine (always seeing that he is thoroughly awake when commencing the act), letting him keep a calendar in which every dry night is marked by a red cross, and so on. With this complaint "nothing succeeds like success," and the confidence that is instilled by these methods may well tip the scale towards cure. Needless to say, punishment in any form for bed wetting is both immoral and futile.

Abnormalities of the urinary tract are not uncommon in enuretics, and should always be looked for and corrected. Twistington Higgins (I944) considers that one case in ten is organic, but Winsbury White (I94I) puts the incidence at a much higher rate. Meatitis, meatal stenosis, vulvitis and vesical calculus are all more or less common accompaniments of enuresis, and a cure may not be attainable until they are dealt with.

3. Frequency.-Perhaps the commonest cause of frequency is detrusor achalasia, and this has been dealt with at some length above. Polyuria gives rise to the symptom, and diabetic melitus vel insipidus must be eliminated. Other causes of frequency are usually accompanied by a greater or less degree of dysuria, and are discussed in the following section. It should be remembered that appendicitis may show itself with frequency as the presenting symptom.

4. Dysuria.-Dysuria means painful or difficult micturition, and these symptoms may be present either singly or together. They nearly always indicate inflammation of the lower urinary passages. In boys balanitis is one of the commonest causes. It may be simply a catarrhal condition, giving rise to reddening and swelling of the prepuce. This may be purely 
a local lesion, or it may be a part of a generalised tendency to catarrhal inflammation of the mucocutaneous junctions, and is then accompanied by blepharitis or soreness at the angles of the mouth (perlèche). An adequate intake of vitamins $A$ and B.I must be insured, and Io per cent sulphanilamide ointment should be applied to the prepuce. The condition, however, may be a purulent one, in which case the prepuce should be irrigated with warm boracic lotion or $I$ in 300 cyllin. If the child has repeated attacks circumcision should be performed during a remission. In circumcised boys an ulcer of the meatus with scab formation, which completely obstructs the urinary outflow, is not uncommon. The scab should be removed with Io vol. hydrogen peroxide and Io per cent sulphanilamide ointment applied. In girls vulvitis is frequently met with. The mucous membrane of the vestibule is reddened, and there may be a thin purulent discharge. This may be secondary to a vaginitis, either catarrhal or gonococcal, which must receive appropriate treatment. Other causes are adhesions of the labia minora and adhesions of the prepuce of the clitoris which should be gently separated by a probe. Masturbation is a common symptom of vulvitis, and it may be a cause. It is a frequent occurrence in young children, and need give rise to no distress. Vulvitis should be treated by the application of euflavine I in I000 aqueous solution, cyllin I in 300 aqueous solution, or Io per cent sulphanilamide ointment.

Cystitis results from the spreading of an infection of the lower urinary passages to the bladder. It is therefore much commoner in girls. In addition to the symptoms of frequency and dysuria the urine is found to contain pus, or at least b. coli. Red cells are often present It frequently happens that the inflammation spreads still higher, so that the ureters and pelves of the kidneys are affected, and pyelitis is produced. The child now develops a swinging temperature, and may become subject to cyanotic or syncopal attacks. Vomiting is common. Finally, the kidney substance may become affected and uraemic symptoms may supervene. In this case the urine will contain casts in addition to blood, pus, and b. coli.

This $\mathrm{b}$. coli infection of the urinary tract is one of the commonest infections of childhood. In every case of obscure pyrexia in early life a catheter specimen of urine should be obtained for pathological examination.

Treatment The first thing to do is to render the urine alkaline. Quite large doses of citrate and bicarbonate may be required to accomplish this, e.g. twenty grains of each every four hours. Medication must be persisted in night and day, or else the morning urine will become acid again. Quite often this is all that is necessary, and the alkalinisation of the urine will coincide with a drop in the temperature to normal limits and the disappearance of abnormalities from the urine. If this occurs the urine should be kept alkaline for two or three weeks. Should symptoms persist small doses of the sulphanilamide group of drugs will usually render the urine sterile. Sulphamethazine is probably the best form to use, as it is not so likely to damage the kidney. Curiously enough the sulphanilamide group is not effective if the infection is due to a streptococcus. In this case acriflavine gr. $\frac{1}{2}-\mathrm{I}$ in enteric coated capsules or ammonium mandelate grs. $\mathrm{v}-\mathrm{xxx}$ according to age should be given. The urine should be rendered acid to methyl red if the latter drug is used. The external genitalia should always be kept scrupulously clean in the urinary infections of childhood, and one of the disinfectants mentioned above should be applied in order to prevent relapses.

Vesical calculus may be the starting-point of any of the above infections, and gives rise to attacks of pain, especially at the end of micturition. Tensesmus is frequent, both on urination and defaecation. Gross haematuria may or may not be present. The diagnosis is confirmed radiologically, and the treatment is surgical removal.

\section{Summary}

Disorders of micturition in childhood are retention, incontinence, frequency and dysuria.

Retention is uncommon, and usually accompanies serious organic nervous disease.

Incontinence is usually intermittent, and constitutes enuresis. Detrusor achalasia, abnormally deep sleep, psycho-neurosis, and local lesions may all play a part in producing the symptom, and each may require treatment.

Dysuria and frequency are most often the result of infection, and general and local treatment is called for. 